\title{
Soluble P-Selectin and the Risk of Primary Graft Dysfunction After Lung Transplantation
}

\author{
Steven M. Kawut, MD, MS, FCCP; Jeffrey Okun, BS; Daichi Shimbo, MD; \\ David J. Lederer, MD, MS; Joao De Andrade, MD; Vibha Lama, MD; \\ Ashish Shah, MD; Aaron Milstone, MD; Lorraine B. Ware, MD, FCCP; \\ Ann Weinacker, MD; Ejigayehu Demissie, MSN; and Jason D. Christie, MD, MS, FCCP; \\ for the Lung Transplant Outcomes Group
}

\begin{abstract}
Background: Platelet activation with subsequent neutrophilic adherence to the vasculature initiates ischemia-reperfusion injury. We hypothesized that higher plasma P-selectin levels reflecting platelet activation would therefore be associated with primary graft dysfunction (PGD) after lung transplantation.

Methods: In a prospective, multicenter cohort study of 376 patients who had undergone lung transplantation between 2002 and 2007, we measured soluble P-selectin levels before lung transplantation and at 6 and $24 \mathrm{~h}$ after lung reperfusion in 20 patients with grade III PGD $\left(\mathrm{PaO}_{2} /\right.$ fraction of inspired oxygen, $<200 \mathrm{~mm} \mathrm{Hg}$ [with alveolar infiltrates seen on chest radiographs]) at $72 \mathrm{~h}$ after transplantation and 61 control subjects without PGD.

Results: Higher postoperative soluble P-selectin levels were associated with an increased risk of PGD at $72 \mathrm{~h}$ after transplantation (odds ratio $[\mathrm{OR}]$ per 1 natural log increase in soluble P-selectin at $6 \mathrm{~h}$ after lung allograft reperfusion, 3.5; 95\% confidence interval $[\mathrm{CI}], 1.01$ to $11.8 ; \mathrm{p}=0.048$ ) and at $24 \mathrm{~h}$ after lung allograft reperfusion $(\mathrm{OR}, 4.8 ; 95 \% \mathrm{CI}, 1.4$ to $16.1 ; \mathrm{p}=0.01)$. Higher preoperative mean pulmonary artery pressure and the use of cardiopulmonary bypass were also associated with an increased risk of PGD.

Conclusion: Higher postoperative soluble P-selectin levels were associated with an increased risk of PGD at $72 \mathrm{~h}$ following lung transplantation.

(CHEST 2009; 136:237-244)

Abbreviations: $\mathrm{ALI}=$ acute lung injury; $\mathrm{CI}=$ confidence interval; $\mathrm{CPB}=$ cardiopulmonary bypass; $\mathrm{FIO}_{2}=$ fraction of inspired oxygen; IQR = interquartile range; $\mathrm{mPAP}=$ mean pulmonary artery pressure; $\mathrm{OR}=$ odds ratio; $\mathrm{PGD}=$ primary graft dysfunction
\end{abstract}

$\mathbf{P}$ rimary graft dysfunction (PGD) is a form of acute lung injury (ALI) occurring immediately after lung transplantation due to ischemia-reperfusion injury. ${ }^{1-4}$ The incidence of PGD ranges from 10 to $25 \%$, and PGD is the leading cause of early posttransplantation morbidity and mortality. ${ }^{1-3,5-7}$ The risk factors for PGD are varied, involving the donor, recipient, and the processes of cold ischemia and reperfusion of the lung allografts. 8,9

Prior studies ${ }^{10-13}$ have demonstrated that the adhesion of neutrophils to the pulmonary vascular endothelium, diapedesis, and infiltration into the vessel wall are key initial steps in ALI and PGD, leading to the capillary leak that characterizes these syndromes. Activated platelets play an integral role in the tethering and

activation of neutrophils with eventual firm adherence to the vascular wall and transit to the interstitial and alveolar spaces. P-selectin is mobilized to the platelet surface from $\alpha$ granules and to the endothelial cell membrane from Weibel-Palade bodies and serves as a receptor to a variety of ligands before being shed in the plasma in soluble form. ${ }^{14}$ Although soluble P-selectin therefore may be of platelet or endothelial origin, it is considered a reliable and valid measure of platelet activation. ${ }^{15,16}$ Animal models of ALI show elevations in soluble P-selectin levels, ${ }^{11}$ suggesting that platelet activation is present. P-selectin may have mechanistic importance in PGD as well because P-selectin blockade (or P-selectin knockout) protected the lung allograft after ischemia and reperfusion in a mouse model. ${ }^{17}$ 
We have previously shown ${ }^{18}$ that soluble P-selectin levels, CD40 ligand levels, and platelet-leukocyte aggregates (the most sensitive measure of platelet activation) increase in parallel after lung transplantation without cardiopulmonary bypass (CPB) compared to nontransplant thoracic surgery, indicating that soluble P-selectin in these patients is most likely shed from platelet sources in response to lung implantation. However, to our knowledge, no previous studies have addressed the relationship between platelet activity and PGD. In the current study, we hypothesized that platelet activation, as measured by increased soluble P-selectin levels, would be associated with a higher risk of PGD in lung transplantation recipients.

\section{Materials AND Materials}

We performed a case-control study nested in a prospective cohort of 376 patients undergoing a first lung transplantation at seven centers in the United States (see Appendix for institutions and investigators). The study sample consisted of 20 randomly selected case patients with PGD grade III and 61 control subjects without PGD (PGD grade 0) enrolled between 2002 and 2007 with sufficient plasma. PGD case patients had diffuse alveolar infiltrates involving the lung allografts and, in the case of a single lung transplant, sparing the native lung, as seen on chest radiographs; $\mathrm{PaO}_{2} /$ fraction of inspired oxygen $\left(\mathrm{FIO}_{2}\right)$ ratio of $<200 \mathrm{~mm} \mathrm{Hg}$; and no other secondary cause of graft dysfunction identified, all at $72 \mathrm{~h}$ after transplantation. This definition has been validated previously. ${ }^{1,2,4,7}$ Control subjects were patients from the cohort with clear lung allografts as determined by chest radiography (PGD grade 0) at $72 \mathrm{~h}$ after transplantation (see online supplement for details).

Informed consent for this study was obtained prior to organ transplantation. Blood samples were obtained in citrated tubes (Vacutainer; Becton Dickinson; Franklin Lakes, NJ) before trans-

From the Department of Medicine (Drs. Kawut and Christie, and Ms. Demissie), University of Pennsylvania School of Medicine, Philadelphia, PA; the Department of Medicine (Drs. Shimbo and Lederer, and Mr. Okun), Columbia University College of Physicians and Surgeons, New York City, NY; the Department of Medicine (Dr. De Andrade), University of Alabama at Birmingham, Birmingham, AL; the Department of Medicine (Dr. Lama), University of Michigan, Ann Arbor, MI; the Department of Surgery (Dr. Shah), Johns Hopkins University, Baltimore, MD; the Department of Medicine (Drs. Milstone and Ware), Vanderbilt University, Nashville, TN; and the Department of Medicine (Dr. Weinacker), Stanford University, Stanford, CA.

This research was supported by National Institutes of Health grants HL04243, HL067771, HL081332, HL087115, and HL081619.

The authors have reported to the ACCP that no significant conflicts of interest exist with any companies/organizations whose products or services may be discussed in this article.

Manuscript received November 16, 2008; revision accepted January 20, 2009.

Reproduction of this article is prohibited without written permission from the American College of Chest Physicians (www.chestjournal. org/site/misc/reprints.xhtml).

Correspondence to: Steven M. Kawut, MD, MS, FCCP, Cardiovascular Institute, Center for Clinical Epidemiology and Biostatistics, Pulmonary, Allergy and Critical Care Division, University of Pennsylvania School of Medicine, 711 Blockley Hall, 423 Guardian Dr, Philadelphia,PA 19104; e-mail: kawut@mail.med.upenn.edu DOI: 10.1378/chest.08-2697 plantation, and at $6 \mathrm{~h}$ and $24 \mathrm{~h}$ after reperfusion of the lung allograft. Samples were centrifuged within $30 \mathrm{~min}$ of collection, and plasma samples were stored at $-80^{\circ} \mathrm{C}$. Clinical variables were categorized and defined using methods published previously. ${ }^{3}$ Soluble P-selectin levels were measured in a central laboratory with an ultrasensitive, solid-phase sandwich, enzyme-linked immunosorbent assay (R\&D Systems; Minneapolis, MN) [see online supplement for details].

\section{Statistical Analysis}

Data were summarized as the mean $\pm \mathrm{SD}$ and median (interquartile range $[\mathrm{IQR}])$, as appropriate. Unpaired $t$ tests, rank sum tests, signed rank tests, and $\chi^{2}$ or Fisher exact tests were used to compare PGD case patients with non-PGD control subjects. Correlations were assessed using Spearman rank correlation coefficients.

Bivariate and multivariate logistic regression models were used to assess the relationship between soluble P-selectin levels at baseline, $6 \mathrm{~h}$, and $24 \mathrm{~h}$ postoperatively and the occurrence of PGD at $72 \mathrm{~h}$ after lung transplantation. Included in the multivariate analysis were potential confounding variables with $p$ values $<0.20$ in bivariate analyses. Potential confounders were included in the models one at a time; significant confounding was indicated by a change in the coefficient of the term for soluble $\mathrm{P}$-selectin $>20 \%$. Mean pulmonary artery pressure (mPAP) at anesthesia induction was considered in quartiles with indicator variables in the regression models; missing data were coded as such in this analysis. Soluble P-selectin levels were log transformed for the regression analysis. Power calculations are provided in the online supplement.

All statistical comparisons were performed using a statistical software package (Stata, version 10.0; Stata Corp; College Station, TX). This research protocol was approved by the institutional review boards at each of the participating centers.

\section{RESUlts}

There were 81 patients in the study sample (Table $1)$. The mean age of the patients was $53 \pm 12$ years, 33 patients $(41 \%)$ were women, and 72 patients (89\%) were non-Hispanic white. Most patients had undergone lung transplantation for COPD, and 25 patients $(31 \%)$ received $\mathrm{CPB}$.

Soluble P-selectin levels before lung transplantation and at 6 and $24 \mathrm{~h}$ after reperfusion of the lung allografts are shown in Figure 1. One patient had a missing preoperative P-selectin level, two had missing levels at $6 \mathrm{~h}$, and one had a missing level at $24 \mathrm{~h}$. In the entire study sample, median soluble P-selectin levels significantly increased from baseline (61 $\mathrm{ng} / \mathrm{mL}$ [IQR, 47 to $80 \mathrm{ng} / \mathrm{mL}])$ to $6 \mathrm{~h}(74 \mathrm{ng} / \mathrm{mL}$ [IQR, 50 to $111 \mathrm{ng} / \mathrm{mL}$ ], $\mathrm{p}<0.001$ vs baseline) and to $24 \mathrm{~h}(69 \mathrm{ng} / \mathrm{mL}$ [IQR, 50 to $99 \mathrm{ng} / \mathrm{mL}$ ], $\mathrm{p}=0.003$ vs baseline) after reperfusion.

Among those PGD and non-PGD patients who did not receive $\mathrm{CPB}$ during the transplantation procedure $(\mathrm{n}=56)$, there was still a significant median increase in soluble P-selectin levels from baseline $(60 \mathrm{ng} / \mathrm{mL}$ [IQR, 46 to $76 \mathrm{ng} / \mathrm{mL}$ ]) to $6 \mathrm{~h}(69$ $\mathrm{ng} / \mathrm{mL}$ [IQR, 45 to $104 \mathrm{ng} / \mathrm{mL}$, p $=0.004$ vs base- 
Table 1-Characteristics of the Study Sample

\begin{tabular}{|c|c|c|}
\hline Characteristics & No. & Data \\
\hline \multicolumn{3}{|l|}{ Recipient variables } \\
\hline Age, yr & 81 & $53 \pm 12$ \\
\hline Female sex & 81 & $33(41)$ \\
\hline Race/ethnicity & 81 & \\
\hline Non-Hispanic white & & $72(89)$ \\
\hline Black & & $8(10)$ \\
\hline Hispanic & & $1(1)$ \\
\hline Other & & $1(1)$ \\
\hline Diagnosis & 81 & \\
\hline COPD & & $37(46)$ \\
\hline Diffuse parenchymal lung disease & & $28(35)$ \\
\hline Cystic fibrosis & & $10(12)$ \\
\hline Other & & $6(7)$ \\
\hline \multicolumn{3}{|l|}{ Donor variables } \\
\hline Age, yr & 81 & $31 \pm 14$ \\
\hline Female sex & 81 & $34(42)$ \\
\hline Race/ethnicity & 81 & \\
\hline Non-Hispanic white & & $61(75)$ \\
\hline Black & & $8(10)$ \\
\hline Hispanic & & $10(12)$ \\
\hline Other & & $2(2)$ \\
\hline \multicolumn{3}{|l|}{ Surgical variables } \\
\hline Bilateral transplant & 81 & $50(62)$ \\
\hline Use of $\mathrm{CPB}$ & 81 & $25(31)$ \\
\hline mPAP at induction, $\mathrm{mm} \mathrm{Hg}$ & 61 & $29 \pm 12$ \\
\hline Ischemic time, $\min$ & 77 & $293(240-352)$ \\
\hline Packed RBCs during first $24 \mathrm{~h}, \mathrm{~mL}$ & 81 & $250(0-1,000)$ \\
\hline Platelets during first $24 \mathrm{~h}, \mathrm{~mL}$ & 81 & $0(0-0)$ \\
\hline Fresh frozen plasma during first $24 \mathrm{~h}, \mathrm{~mL}$ & 81 & $0(0-450)$ \\
\hline
\end{tabular}

Values are given as the mean $\pm \mathrm{SD}$, No. (\%), or median (IQR).

line) and possibly to $24 \mathrm{~h}(66 \mathrm{ng} / \mathrm{mL}$ [IQR, 45 to 95 $\mathrm{ng} / \mathrm{mL}], \mathrm{p}=0.09$ vs baseline) after reperfusion. Focusing only on the non-PGD control group (with or without CPB) $[n=61]$, we again found that median

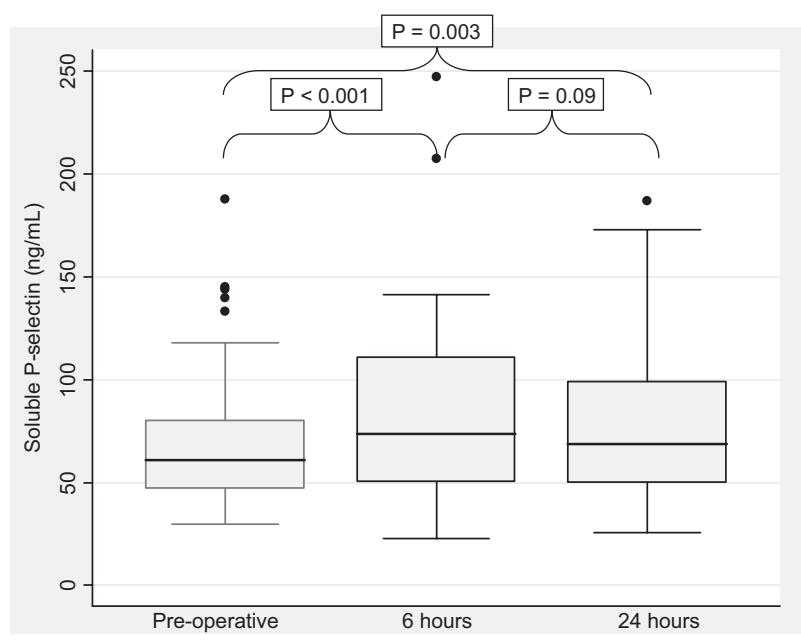

FIGURE 1. Box-and-whisker plots of soluble P-selectin levels preoperatively and at 6 and $24 \mathrm{~h}$ after lung allograft reperfusion. Horizontal line $=$ median; box $=25$ th and 75 th percentiles; whiskers $=$ adjacent values
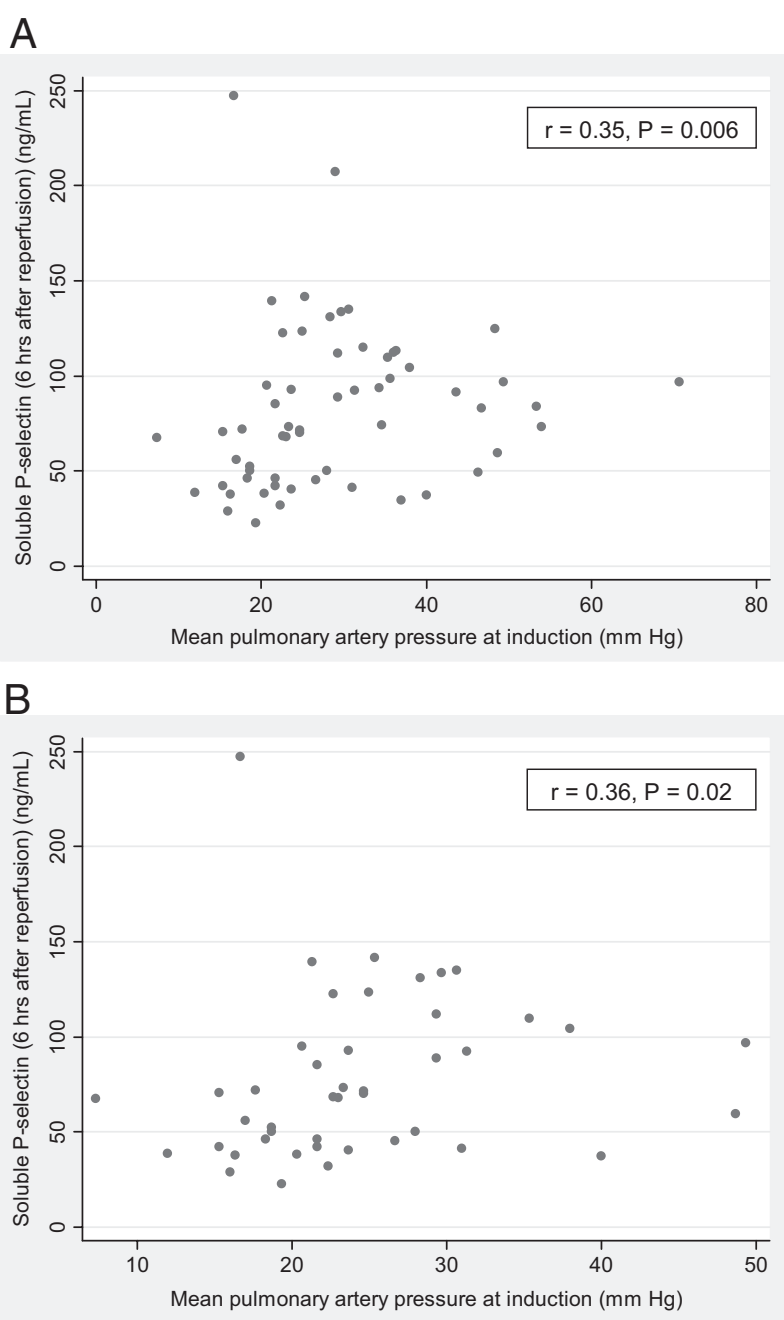

Figure 2. Scatterplots of soluble P-selectin levels at $6 \mathrm{~h}$ after lung allograft reperfusion vs mPAP at induction. A: all patients $(\mathrm{n}=59)$. B: patients not receiving $\mathrm{CPB}(\mathrm{n}=44)$.

soluble P-selectin levels increased from baseline $(60$ $\mathrm{ng} / \mathrm{mL}$ [IQR, 46 to $79 \mathrm{ng} / \mathrm{mL}])$ to $6 \mathrm{~h}(70 \mathrm{ng} / \mathrm{mL}$ [IQR, 46 to $109 \mathrm{ng} / \mathrm{mL}$ ], $\mathrm{p}=0.002$ vs baseline) and possibly to $24 \mathrm{~h}(63 \mathrm{ng} / \mathrm{mL}$ [IQR, 45 to $97 \mathrm{ng} / \mathrm{mL}$ ], $\mathrm{p}=0.07$ vs baseline) after reperfusion.

Patients with diffuse parenchymal lung disease in the entire study sample may have had higher median soluble P-selectin levels before transplantation than patients with COPD (64 ng/mL [IQR, 59 to 87 $\mathrm{ng} / \mathrm{mL}$ ] vs $56 \mathrm{ng} / \mathrm{mL}$ [IQR, 38 to $69 \mathrm{ng} / \mathrm{mL}$ ], respectively; $\mathrm{p}=0.06$ ) Although mPAP at anesthesia induction for lung transplantation was not associated with soluble P-selectin levels at baseline in the entire study sample $(r=0.02 ; \mathrm{p}=0.93)$, there were significant direct associations between MPAP at anesthesia induction and soluble P-selectin levels at 6 and $24 \mathrm{~h}$ after lung transplantation in the entire study sample and in those who did not receive CPB (Fig 2, 3). In those patients who received $\mathrm{CPB}$, there were no 


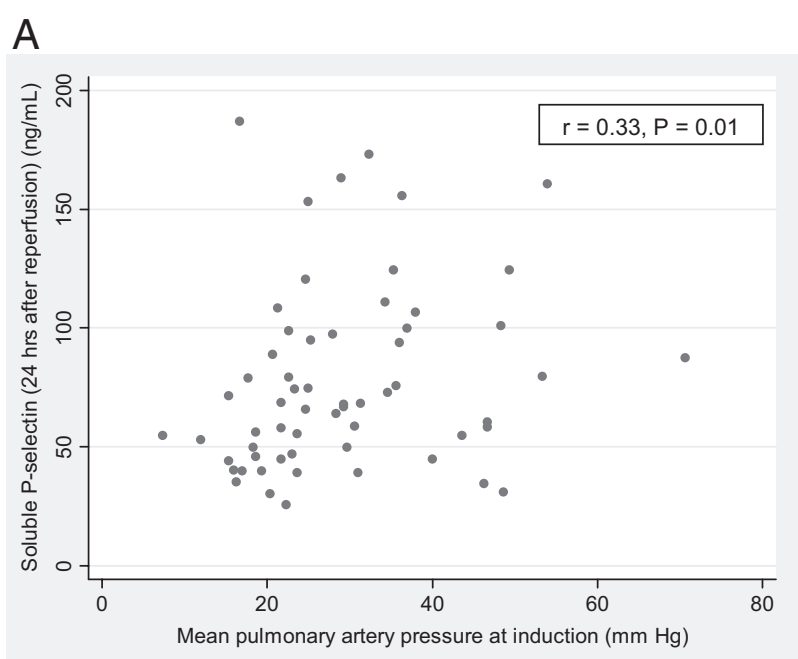

B

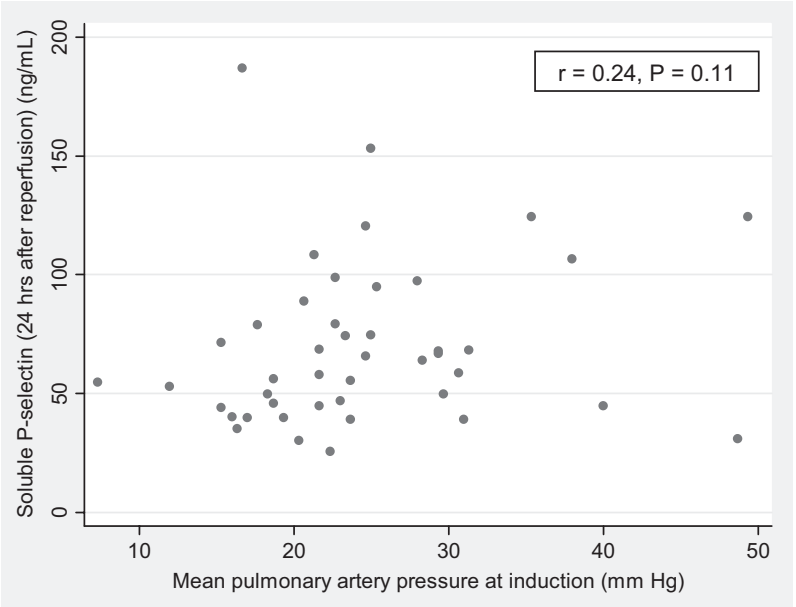

Figure 3. Scatterplots of soluble P-selectin levels at $24 \mathrm{~h}$ after lung allograft reperfusion vs $\mathrm{mPAP}$ at induction. A: all patients $(\mathrm{n}=60)$. B: patients not receiving CPB $(\mathrm{n}=44)$.

associations between CPB time and soluble P-selectin levels at any time point (data not shown).

We then compared PGD case patients to nonPGD control subjects (Table 2). PGD case patients tended to be younger than control subjects; however, there were no sex differences between the groups. PGD case patients were less likely to be nonHispanic white and more likely to be black than control subjects. Case patients with PGD were more likely to have undergone transplantation for diffuse parenchymal lung disease than for COPD. PGD case patients had higher mPAP levels at induction, had more frequently used $\mathrm{CPB}$, and had required transfusion of more blood products during transplantation and during the first $24 \mathrm{~h}$ postoperatively.

Case patients with PGD had median soluble Pselectin levels at baseline that were similar to those of control subjects without PGD (64 ng/mL [IQR, 56 to $83 \mathrm{ng} / \mathrm{mL}$ ] vs $60 \mathrm{ng} / \mathrm{mL}$ [IQR, 46 to $79 \mathrm{ng} / \mathrm{mL}$ ], respectively; $\mathrm{p}=0.50$ ) [Fig 4]. However, case patients with PGD had higher median soluble P-selectin levels than non-PGD control subjects at $6 \mathrm{~h}(97 \mathrm{ng} / \mathrm{mL}$ [IQR, 73 to $112 \mathrm{ng} / \mathrm{mL}$ ] vs $70 \mathrm{ng} / \mathrm{mL}$ [IQR, 46 to 109 $\mathrm{ng} / \mathrm{mL}]$, respectively; $\mathrm{p}=0.03)$ and at $24 \mathrm{~h}(91 \mathrm{ng} / \mathrm{mL}$ [IQR, 74 to $118 \mathrm{ng} / \mathrm{mL}$ ] vs $63 \mathrm{ng} / \mathrm{mL}$ [IQR, 45 to 97 $\mathrm{ng} / \mathrm{mL}$, respectively; $\mathrm{p}=0.006$ ) after lung reperfusion.

Higher soluble P-selectin levels at $6 \mathrm{~h}$ after lung allograft reperfusion were associated with an increased risk of PGD (odds ratio [OR] per 1 natural log increase in soluble P-selectin level, 3.5; $95 \%$ confidence interval [CI], 1.01 to $11.8 ; \mathrm{p}=0.048)$, as they were at $24 \mathrm{~h}$ after lung reperfusion (OR per 1 natural log increase in soluble P-selectin level, 4.8; 95\% CI, 1.4 to 16.1; $\mathrm{p}=0.01$ ) [Table 3]. Adjustment for a variety of variables, including sex, race, or pulmonary diagnosis, did not affect the results. Similarly, there was no change in the findings after adjustment for the use of blood products, such as packed RBCs, platelets, or fresh frozen plasma. The associations between soluble P-selectin levels and PGD case status seemed to be explained in part by the use of CPB because adjustment for this factor significantly reduced the effect estimates of soluble P-selectin levels.

\section{Discussion}

PGD contributes significantly to overall morbidity and is the major cause of early death following lung transplantation. We have shown that higher soluble P-selectin levels were associated with the occurrence of PGD in this case-control study nested within a large multicenter cohort of patients undergoing lung transplantation. Although increased mPAP and CPB are traditional risk factors for PGD (and were risk factors in our study), we have shown that increased soluble P-selectin levels and platelet activation may explain the mechanism of these associations. We have previously characterized PGD in terms of coagulation/fibrinolysis, endothelial dysfunction, inflammation, and oxidative stress. ${ }^{19-21}$ However, these are the first data showing the importance of increased platelet activation in patients with PGD following human lung transplantation.

Platelets contribute to the course of ischemiareperfusion injury in patients who have undergone transplants of other solid organs, such as the liver ${ }^{22}$; however, there is less known about this process in the lung. ${ }^{23}$ Okada et $\mathrm{al}^{24}$ showed that the accumulation of platelets in preserved and transplanted rat lungs was associated with the degree of reperfusion injury. Platelet adherence also resulted in capillary 
Table 2-Characteristics of PGD Case Patients and Control Subjects

\begin{tabular}{|c|c|c|c|c|}
\hline Characteristics & No. & Case Patients $(\mathrm{n}=20)$ & Control Subjects $(\mathrm{n}=61)$ & $\mathrm{p}$ Value \\
\hline \multicolumn{5}{|l|}{ Recipient variables } \\
\hline Age, yr & 81 & $49 \pm 14$ & $54 \pm 12$ & 0.18 \\
\hline Female sex & 81 & $8(40)$ & $25(42)$ & 0.94 \\
\hline Race/ethnicity & 81 & & & 0.02 \\
\hline Non-Hispanic white & & $15(75)$ & $57(93)$ & \\
\hline Black & & $5(25)$ & $3(5)$ & \\
\hline Hispanic & & & $1(2)$ & \\
\hline Diagnosis & 81 & & & 0.03 \\
\hline COPD & & $5(25)$ & $32(52)$ & \\
\hline Diffuse parenchymal lung disease & & $12(60)$ & $16(26)$ & \\
\hline Cystic fibrosis & & $1(5)$ & $9(15)$ & \\
\hline Other & & $2(10)$ & $4(7)$ & \\
\hline \multicolumn{5}{|l|}{ Donor variables } \\
\hline Age, yr & 81 & $30 \pm 13$ & $32 \pm 14$ & 0.69 \\
\hline Female sex & 81 & $8(40)$ & $25(41)$ & 0.94 \\
\hline Race/ethnicity & 81 & & & 0.30 \\
\hline Non-Hispanic white & & $18(90)$ & $43(71)$ & \\
\hline Black & & & $8(13)$ & \\
\hline Hispanic & & $2(10)$ & $8(13)$ & \\
\hline Other & & & $2(3)$ & \\
\hline \multicolumn{5}{|l|}{ Surgical variables } \\
\hline Bilateral transplant & 81 & $13(65)$ & $37(61)$ & 0.73 \\
\hline Use of $\mathrm{CPB}$ & 81 & $14(70)$ & $11(18)$ & $<0.001$ \\
\hline mPAP at induction, $\mathrm{mm} \mathrm{Hg}$ & 61 & $40 \pm 14$ & $25 \pm 9$ & $<0.001$ \\
\hline Ischemic time, $\min$ & 77 & $286(257-375)$ & $300(235-352)$ & 0.50 \\
\hline Packed RBCs during first $24 \mathrm{~h}, \mathrm{~mL}$ & 81 & $875(0-1,500)$ & $250(0-750)$ & 0.05 \\
\hline Platelets during first $24 \mathrm{~h}, \mathrm{~mL}$ & 81 & $0(0-622)$ & $0(0-0)$ & $<0.001$ \\
\hline Fresh frozen plasma during first $24 \mathrm{~h}, \mathrm{~mL}$ & 81 & $363(0-1,053)$ & $0(0-0)$ & 0.002 \\
\hline
\end{tabular}

Values are given as the mean $\pm \mathrm{SD}$, No. $(\%)$, or median (IQR), unless otherwise indicated.

congestion. Other studies ${ }^{17,25}$ of animal models of ischemia-reperfusion injury and ALI have not only documented platelet-mediated leukocyte infiltration in the lungs, but also specifically identified platelet-

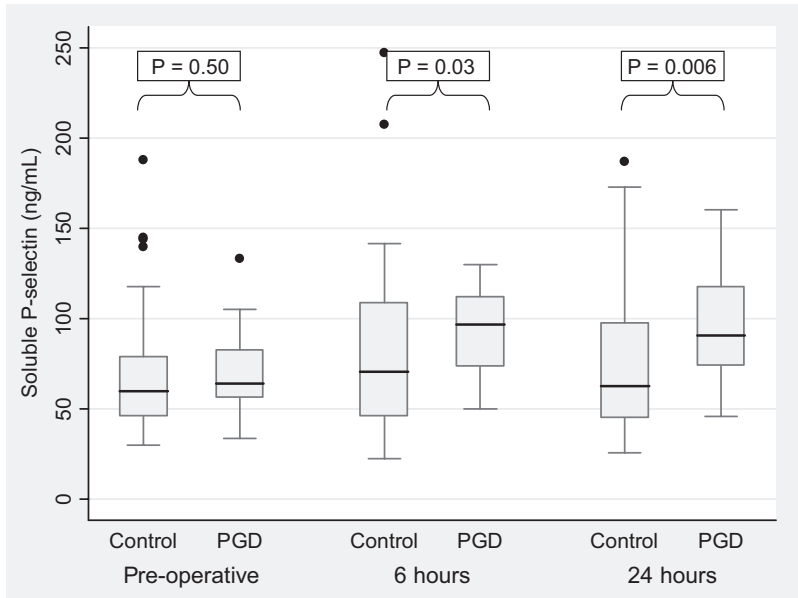

Figure 4. Box-and-whisker plots of soluble P-selectin levels for PGD case patients and control subjects preoperatively and at 6 and $24 \mathrm{~h}$ after lung allograft reperfusion. Horizontal line $=$ median; box $=25$ th and 75 th percentiles; whiskers $=$ adjacent values. derived P-selectin as the key molecule in this process. One study ${ }^{17}$ utilized a rat model of orthotopic left lung transplantation after $6 \mathrm{~h}$ of hypothermic preservation. The administration of blocking anti-Pselectin antibody before reperfusion reduced pulmonary vascular resistance, increased $\mathrm{PaO}_{2}$, and improved survival. P-selectin knockout mice subjected to 30 min of pulmonary ischemia followed by reperfusion also showed significant reductions in neutrophil infiltration, increases in $\mathrm{PaO}_{2}$, and prolonged survival compared to wild-type mice. A model of lung ischemia-reperfusion in rabbits confirmed the rolling and adherence of platelets mediated by platelet P-selectin in the pulmonary vasculature after reperfusion. ${ }^{25}$

Zarbock et al ${ }^{26}$ have shown that platelets play an important role in the accumulation of neutrophils in the intravascular, interstitial, and intraalveolar spaces of the lung in ALI. Platelet depletion in this model prevented abnormalities in gas exchange, accumulation of neutrophils in all three compartments, and protein leak. Antibodies against P-selectin prevented the formation of circulating platelet-neutrophil aggregates, decreased neutrophils in BAL fluid, improved the $\mathrm{PaO}_{2} / \mathrm{FIO}_{2}$ ratio, and prolonged survival in this model. In addition, wild-type mice with ALI 
Table 3-Logistic Regression Models for the Association of P-selectin Levels at 6 and 24 h With PGD

\begin{tabular}{|c|c|c|c|c|c|c|}
\hline Variables & $\begin{array}{l}\text { OR for PGD per } \\
1 \mathrm{ln} \text { Increase in } \\
\text { P-selectin at } 6 \mathrm{~h} \\
\text { After Reperfusion }\end{array}$ & $95 \% \mathrm{CI}$ & $\mathrm{p}$ Value & $\begin{array}{l}\text { OR for PGD per } \\
1 \mathrm{ln} \text { Increase in } \\
\text { P-selectin at } 24 \mathrm{~h} \\
\text { After Reperfusion }\end{array}$ & $95 \% \mathrm{CI}$ & $\mathrm{p}$ Value \\
\hline Unadjusted & 3.5 & $1.01-11.8$ & 0.048 & 4.8 & $1.4-16.1$ & 0.01 \\
\hline \multicolumn{7}{|l|}{ Adjusted for } \\
\hline Recipient age & 2.9 & $0.8-10.9$ & 0.11 & 4.4 & $1.2-16.0$ & 0.02 \\
\hline Recipient sex & 4.8 & $1.4-16.7$ & 0.01 & 4.8 & $1.4-16.7$ & 0.01 \\
\hline Recipient diagnosis & 4.8 & $1.1-20.6$ & 0.04 & 5.1 & $1.4-19.2$ & 0.02 \\
\hline Recipient race/ethnicity & 4.1 & $1.1-14.7$ & 0.03 & 6.9 & $1.8-27.3$ & 0.005 \\
\hline mPAP at induction & 3.8 & $1.2-18.7$ & 0.07 & 4.8 & $1.2-18.7$ & 0.025 \\
\hline Bilateral transplant & 3.5 & $1.0-12.0$ & 0.05 & 4.9 & $1.4-17.1$ & 0.01 \\
\hline Use of $\mathrm{CPB}$ & 2.1 & $0.5-8.8$ & 0.29 & 2.9 & $0.7-11.3$ & 0.13 \\
\hline Ischemic time & 3.2 & $0.9-11.5$ & 0.07 & 4.2 & $1.2-14.8$ & 0.03 \\
\hline Packed RBCs during first $24 \mathrm{~h}$ & 3.7 & $1.0-13.2$ & 0.04 & 5.1 & $1.5-17.6$ & 0.01 \\
\hline Platelets during first $24 \mathrm{~h}$ & 4.9 & $1.4-16.9$ & 0.06 & 4.9 & $1.4-16.9$ & 0.01 \\
\hline Fresh frozen plasma during first $24 \mathrm{~h}$ & 2.9 & $0.8-10.4$ & 0.10 & 4.5 & $1.3-15.6$ & 0.02 \\
\hline
\end{tabular}

$\ln =$ natural $\log$.

and reconstituted with bone marrow from P-selectin knockout mice (thus permitting endothelial P-selectin but not megakaryocyte P-selectin expression) demonstrated better gas exchange and decreased neutrophil accumulation in the intravascular, interstitial, and intraalveolar spaces of the lung compared to wild-type mice with intact bone marrow. Another study ${ }^{27}$ showed that platelet P-selectin was critical to the proinflammatory phenotype of endothelial dysfunction induced by high-tidal volume ventilation.

We have previously shown ${ }^{18}$ that human lung transplantation itself is associated with platelet activation, even in the absence of traditional risk factors such as significant pulmonary hypertension and CPB. Our prospective cohort study 18 of patients undergoing lung transplantation without $\mathrm{CPB}$ and patients undergoing nontransplantation thoracic surgery showed significant increases in levels of soluble P-selectin, CD40 ligand, and circulating plateletmonocyte conjugates in the lung transplantation patients compared to the thoracic surgery patients. Interestingly, the increases in these platelet markers in the lung transplantation recipients were associated with decreases in platelet count, suggesting that more platelet activation was associated with greater platelet consumption or trapping, presumably in the lung allografts. These findings suggest that the transplantation procedure leads to platelet activation, even in the absence of CPB. Importantly, the persistence of the association between soluble P-selectin levels and PGD in the current study, despite adjustment for the use of blood products, indicates that transfusion does not account for our findings.

Colombat et $\mathrm{al}^{28}$ have confirmed that platelet trapping occurs in the newly perfused lung allografts after human lung transplantation and has a signifi- cant impact on oxygenation and allograft function. These investigators performed lung sampling 15 to 30 min after reperfusion. Platelet aggregation in the venular plexus was more prominent in the lung transplantation samples than in samples of lung tissue from control subjects. The finding of $\mathrm{P}$ selectin-stained platelets in the vascular lumen after lung transplantation was associated with a longer duration of mechanical ventilation, lower $\mathrm{PaO}_{2} / \mathrm{FIO}_{2}$ ratio, and pulmonary edema, as shown by chest radiography.

The association between pulmonary hypertension and PGD is complex and poorly understood. Some studies $^{3}$ have suggested that only the diagnosis of pulmonary arterial hypertension itself increases the risk of PGD; other studies ${ }^{29}$ suggest that each higher increment of pulmonary artery pressure (from any underlying lung disease) translates to an increase in risk of PGD. In addition, because patients with significant pulmonary hypertension require $\mathrm{CPB}$ to undergo the transplantation procedure, it is difficult to tease out the respective causal roles. We showed that higher mPAP at induction was associated with higher soluble P-selectin levels both at 6 and $24 \mathrm{~h}$ after lung transplantation. This association appeared to persist even in those patients who did not require $\mathrm{CPB}$, suggesting that preoperative pulmonary vascular disease results in platelet activation after lung transplantation independent of CPB. It is possible that long-standing pulmonary hypertension or right ventricular dysfunction may result in platelet defects leading to heightened susceptibility to an activated pulmonary vascular endothelium after transplantation. The compete lack of association between mPAP and soluble P-selectin levels at baseline suggests that some trigger is necessary to unmask this process. 
There are several limitations to our study. First, PGD encompasses a spectrum of injury; we studied the extremes of this spectrum. Future prospective cohort studies should include patients with PGD grades I and II. Second, we intentionally did not match the control subjects to case patients in terms of pulmonary diagnosis or CPB use because such matching can introduce bias and actually decrease efficiency in certain situations. We did however adjust (or "control") for differences in baseline covariates between case patients and control subjects in multivariate analyses, which is the preferable methodological approach in a study such as ours. Of course, the possibility of unmeasured or residual confounding exists.

In this study, we have provided the first evidence that elevated levels of soluble P-selectin are associated with PGD in human lung transplantation. These data and the strong body of evidence from animal models demonstrating that interference with $\mathrm{P}$ selectin leads to attenuation of ischemia-reperfusion injury make targeting platelet activation a promising therapeutic approach in humans undergoing lung transplantation.

ACKNOWLEDGMENT: We appreciate the technical assistance of Rebekah Boyle, MS, and April Perry, MT.

\section{APPENDIX}

Sites of and Participants in the Lung Transplant Outcomes Group

University of Alabama, Birmingham: Keith Wille, MD; Joao de Andrade, MD; and Tonja Meadows, RN.

Columbia University: David Lederer, MD; Selim Arcasoy, MD; Joshua Sonett, MD; Jessie Wilt, MD; Frank D’Ovidio, MD; Nadine Al-Naamani, MD; Robert Sorabella, BA; Catherine Forster, BA; Michael Koeckert, BA; Jeffrey Okun, BA; Nilani Ravichandran, FNP-C; Genevieve Reilly, FNP-C; and Debbie Rybak, BA.

Johns Hopkins University: Jonathan Orens, MD; and Ashish Shah, MD.

University of Michigan: Vibha Lama, MD, MS; Fernando Martinez, MD, MS; and Emily Galopin, BS.

University of Pennsylvania (Coordinating Site): Jason D. Christie, MD, MS; Steven M. Kawut, MD, MS; Alberto Pocchetino, MD; Ejigayehu Demissie, MSN; Robert M. Kotloff, MD; Vivek N. Ahya, MD; Jeffrey Sager, MD, MS; Denis Hadjiliadis, MD, MHS; James C. Lee, MD; and Richard Aplenc, MD.

Stanford University: Ann Weinacker, MD; Ramona Doyle, MD; Susan Spencer Jacobs, MSN; and Val Scott, MSN.

Vanderbilt University: Aaron Milstone, MD; Lorraine Ware, MD; E. Wesley Ely, MD, MPH; and Stacy Kelley-Blackburn, RN.

\section{REFERENCES}

1 Christie JD, Bavaria JE, Palevsky HI, et al. Primary graft failure following lung transplantation. Chest 1998; 114:51-60

2 King RC, Binns OA, Rodriguez F, et al. Reperfusion injury significantly impacts clinical outcome after pulmonary transplantation. Ann Thorac Surg 2000; 69:1681-1685
3 Christie JD, Kotloff RM, Pochettino A, et al. Clinical risk factors for primary graft failure following lung transplantation. Chest 2003; 124:1232-1241

4 Christie JD, Carby M, Bag R, et al. Report of the ISHLT Working Group on Primary Lung Graft Dysfunction: part II. Definition: a consensus statement of the International Society for Heart and Lung Transplantation. J Heart Lung Transplant 2005; 24:1454-1459

5 de Perrot M, Sekine Y, Fischer S, et al. Interleukin-8 release during early reperfusion predicts graft function in human lung transplantation. Am J Respir Crit Care Med 2002; 165:211-215

6 Christie JD, Kotloff RM, Ahya VN, et al. The effect of primary graft dysfunction on survival after lung transplantation. Am J Respir Crit Care Med 2005; 171:1312-1316

7 Christie JD, Sager JS, Kimmel SE, et al. Impact of primary graft failure on outcomes following lung transplantation. Chest 2005; 127:161-165

8 de Perrot M, Bonser RS, Dark J, et al. Report of the ISHLT Working Group on Primary Lung Graft Dysfunction: part III. Donor-related risk factors and markers. J Heart Lung Transplant 2005; 24:1460-1467

9 Barr ML, Kawut SM, Whelan TP, et al. Report of the ISHLT Working Group on Primary Lung Graft Dysfunction: part IV. Recipient-related risk factors and markers. J Heart Lung Transplant 2005; 24:1468-1482

10 Donnelly SC, Haslett C, Dransfield I, et al. Role of selectins in development of adult respiratory distress syndrome. Lancet 1994; 344:215-219

11 Hirose M, Murai T, Kawashima H. Elevation of rat plasma P-selectin in acute lung injury. Biochim Biophys Acta 2007; 1772:382-389

12 Sakamaki F, Ishizaka A, Handa M, et al. Soluble form of P-selectin in plasma is elevated in acute lung injury. Am J Respir Crit Care Med 1995; 151:1821-1826

13 Bozza FA, Shah AM, Weyrich AS, et al. Amicus or adversary: platelets in lung biology, acute injury, and inflammation. Am J Respir Cell Mol Biol 2009; 40:123-134

14 Furman MI, Benoit SE, Barnard MR, et al. Increased platelet reactivity and circulating monocyte-platelet aggregates in patients with stable coronary artery disease. J Am Coll Cardiol 1998; 31:352-358

15 Abrams CS, Ellison N, Budzynski AZ, et al. Direct detection of activated platelets and platelet-derived microparticles in humans. Blood 1990; 75:128-138

16 Hartwell DW, Mayadas TN, Berger G, et al. Role of Pselectin cytoplasmic domain in granular targeting in vivo and in early inflammatory responses. J Cell Biol 1998; 143:1129_ 1141

17 Naka Y, Toda K, Kayano K, et al. Failure to express the $\mathrm{P}$-selectin gene or P-selectin blockade confers early pulmonary protection after lung ischemia or transplantation. Proc Natl Acad Sci U S A 1997; 94:757-761

18 Sternberg DI, Shimbo D, Kawut SM, et al. Platelet activation in the postoperative period after lung transplantation. J Thorac Cardiovasc Surg 2008; 135:679-684

19 Covarrubias M, Ware LB, Kawut SM, et al. Plasma intercellular adhesion molecule-1 and von Willebrand factor in primary graft dysfunction after lung transplantation. Am J Transplant 2007; 7:2573-2578

20 Christie JD, Robinson N, Ware LB, et al. Association of protein $\mathrm{C}$ and type 1 plasminogen activator inhibitor with primary graft dysfunction. Am J Respir Crit Care Med 2007; 175:69-74

21 Hoffman SA, Wang L, Shah CV, et al. Plasma cytokines and chemokines in primary graft dysfunction post-lung transplantation. Am J Transplant 2009; 9:389-396 
22 Porte RJ, Blauw E, Knot EA, et al. Role of the donor liver in the origin of platelet disorders and hyperfibrinolysis in liver transplantation. J Hepatol 1994; 21:592-600

23 Ovechkin AV, Lominadze D, Sedoris KC, et al. Lung ischemiareperfusion injury: implications of oxidative stress and plateletarteriolar wall interactions. Arch Physiol Biochem 2007; 113:1-12

24 Okada Y, Marchevsky AM, Zuo XJ, et al. Accumulation of platelets in rat syngeneic lung transplants: a potential factor responsible for preservation-reperfusion injury. Transplantation 1997; 64:801-806

25 Roberts AM, Ovechkin AV, Mowbray JG, et al. Effects of pulmonary ischemia-reperfusion on platelet adhesion in subpleural arterioles in rabbits. Microvasc Res 2004; 67:29-37
26 Zarbock A, Singbartl K, Ley K. Complete reversal of acidinduced acute lung injury by blocking of platelet-neutrophil aggregation. J Clin Invest 2006; 116:3211-3219

27 Yiming MT, Lederer DJ, Sun L, et al. Platelets enhance endothelial adhesiveness in high tidal volume ventilation. Am J Respir Cell Mol Biol 2008; 39:569-575

28 Colombat M, Castier Y, Leseche G, et al. Early expression of adhesion molecules after lung transplantation: evidence for a role of aggregated P-selectin-positive platelets in human primary graft failure. J Heart Lung Transplant 2004; 23:1087-1092

29 Whitson BA, Nath DS, Johnson AC, et al. Risk factors for primary graft dysfunction after lung transplantation. J Thorac Cardiovasc Surg 2006; 131:73-80 